\title{
Liposomal Encapsulated Rhodomyrtone: A Novel Antiacne Drug
}

\author{
Julalak Chorachoo, ${ }^{1}$ Thanaporn Amnuaikit, ${ }^{2}$ and Supayang P. Voravuthikunchai ${ }^{1}$ \\ ${ }^{1}$ Natural Products Research Center and Department of Microbiology, Faculty of Science, Prince of Songkla University, \\ Hat Yai 90112, Thailand \\ ${ }^{2}$ Department of Pharmaceutical Technology, Faculty of Pharmaceutical Sciences, Prince of Songkla University, \\ Hat Yai 90112, Thailand \\ Correspondence should be addressed to Supayang P. Voravuthikunchai; supayang.v@psu.ac.th
}

Received 25 January 2013; Accepted 23 April 2013

Academic Editor: Shu-Ming Wang

Copyright (C) 2013 Julalak Chorachoo et al. This is an open access article distributed under the Creative Commons Attribution License, which permits unrestricted use, distribution, and reproduction in any medium, provided the original work is properly cited.

\begin{abstract}
Rhodomyrtone isolated from the leaves of Rhodomyrtus tomentosa possesses antibacterial, anti-inflammatory, and anti-oxidant activities. Since rhodomyrtone is insoluble in water, it is rather difficult to get to the target sites in human body. Liposome exhibited ability to entrap both hydrophilic and hydrophobic compounds and easily penetrate to the target site. The present study aimed to develop a novel liposomal encapsulated rhodomyrtone formulations. In addition, characterization of liposome, stability profiles, and their antiacne activity were performed. Three different formulations of total lipid concentrations 60,80 , and $100 \mu \mathrm{mol} / \mathrm{mL}$ were used. Formulation with $60 \mu \mathrm{mol} / \mathrm{mL}$ total lipid (phosphatidylcholine from soybean and cholesterol from lanolin in $4: 1$, $\mathrm{w} / \mathrm{w})$ exhibited the highest rhodomyrtone encapsulation efficacy $(65.47 \pm 1.7 \%)$, average particle size $(209.56 \pm 4.8 \mathrm{~nm})$, and $\zeta$ potential $(-41.19 \pm 1.3 \mathrm{mV})$. All formulations demonstrated good stability when stored for 2 months in dark at $4^{\circ} \mathrm{C}$ as well as room temperature. Minimal inhibitory concentration and minimal bactericidal concentration values of liposomal formulation against 11 clinical bacterial isolates and reference strains ranged from 1 to 4 and from 4 to $64 \mu \mathrm{g} / \mathrm{mL}$, respectively, while those of rhodomyrtone were $0.25-1$ and $0.5-2 \mu \mathrm{g} / \mathrm{mL}$, respectively. The MIC and MBC values of liposome formulation were more effective than topical drugs against Staphylococcus aureus and Staphylococcus epidermidis.
\end{abstract}

\section{Introduction}

Acne vulgaris is a common human skin disease that affects $80 \%$ of young people worldwide who aged between 11 to 30 years [1]. Pathogenesis of acne lesion formation is multifactorial including initial colonization by Propionibacterium acne, Staphylococcus epidermidis, and Staphylococcus aureus, followed by lipolytic enzyme production, sebum excretion, comedogenesis, certain inflammatory mediators involving sebaceous hyperplasia, follicular hyperkeratinization, hormone imbalance, and immune hypersensitivity [2-4]. In addition, free radicals generated by environmental factors such as toxins and UV rays of sunlight can attack and damage the vital components of healthy skin cells, leading to skin problems such as wrinkles, scars, age spots, and acne lesion.

Numerous treatments including topical application [5, 6], oral administration of antibiotics [7], oral contraceptives
$[8,9]$, and antioxidants [10] can improve control of mild to moderate acne. Inevitably, the use of antibiotics has resulted in increase in antibiotic resistant acne-inducing bacterial strains [11]. Recently, oral isotretinoin has been claimed to be the most effective therapy and its use begins in severe disease cases. However, its use is limited by teratogenicity and several side effects [6]. Therefore, therapeutic agents, predominantly from natural products, may provide an appropriate approach to control these problems.

Antimicrobial and antioxidant properties of various phytochemicals isolated from Thai medicinal plants have been reported [11, 12]. As a part of our on-going research in developing a topical applicative medication to alleviate skin infections, rhodomyrtone isolated from the leaves of Rhodomyrtus tomentosa (Aiton) Hassk. (Family Myrtaceae) was of interest to us. Crude extract from the leaves and rhodomyrtone have been reported to possess both very strong antibacterial 
activity [13-15] and antioxidant property [16]. In spite of its potent biological activity, rhodomyrtone is highly insoluble in water and difficult to get to target sites.

The use of liposomes as drug carriers has been well documented [17, 18]. There are several reports indicating the advantages of the use of liposomal substance as carriers. Liposomes are composed of lipids similar to those present in biological membranes; therefore, they are expected to be biocompatible, biodegradable, practically nonimmunogenic, and nontoxic $[19,20]$. In addition, liposomes are well suited for delivery of therapeutic agents because they usually provide a sustained drug releasing their content slowly, gradually, and increase overall drug efficacy. Therefore, the objectives of this study were (i) to develop novel liposomal encapsulated rhodomyrtone formulations, (ii) to characterize their stability profiles, and (iii) to investigate their antiacne activities.

\section{Material and Methods}

2.1. Rhodomyrtone. Rhodomyrtone, a pure compound from the leaves of Rhodomyrtus tomentosa, was isolated according to the previously described method [21].

\subsection{Preparation of Liposomal Encapsulated Rhodomyrtone.} Liposomal encapsulated rhodomyrtone was prepared by modified ethanol injection method [22]. Rhodomyrtone was dissolved in absolute ethanol (Merck, Germany) to get concentration of $100 \mathrm{mg} / \mathrm{mL}$. Lipid phase was prepared as 60,80 , and $100 \mu \mathrm{mol} / \mathrm{mL}$ total with lipid concentration by dissolving phosphatidylcholine from soybean (Sigma, USA) and cholesterol from lanolin (Fluka, Japan) with ratio of $4: 1$ in $10 \mathrm{~mL}$ ethanol. $10 \mu \mathrm{L}$ of rhodomyrtone was added in the above lipid suspension followed by sonication for $30 \mathrm{~min} .10 \mathrm{~mL}$ of sonicate MilliQ water and lipid phase was warmed in water bath separately till the temperature of both phase reached $60^{\circ} \mathrm{C}$. Water phase was mixed with lipid phase and the dispersion mixture was continually mixed for five minutes. The mixture was poured into a round bottle flask connected to a rotary evaporator (Eyela Rotary Vacuum Evaporator N-100 series, Tokyo, Japan) to get rid of ethanol. Subsequently, liposomal encapsulated rhodomyrtone was transferred into a glass bottle, sealed, and stored till further use.

2.2.1. Size Measurement and $\zeta$-Potential. Size and $\zeta$-potential of liposomal samples were determined by $\zeta$-potential analyzer (Zeta PALS, Brookhaven). $10 \mu \mathrm{L}$ of each liposomal suspension was taken and suitably diluted in distilled water, and $z$-average mean and $\zeta$-potential were measured. All measurements were made for three times at $25^{\circ} \mathrm{C}$.

2.2.2. Scanning Electron Microscope Observations. Morphological and particle sizes of prepared liposomal encapsulated rhodomyrtone formulations have been investigated by SEM (Quanta 400, FEI, Czech Republic). Briefly, $200 \mu \mathrm{L}$ of liposome formulation was diluted with $3 \mathrm{~mL}$ MilliQ water. A drop of diluted liposome was allowed to dry on the cover slip and then stained with crystal violet solution for $1 \mathrm{~min}$. Excess dye was rinsed out with water followed by fixing with Gram's iodine solution for $1 \mathrm{~min}$ [23]. The sample was then coated with gold in a sputter coater under an argon atmosphere $(50 \mathrm{~Pa})$ at $50 \mathrm{~mA}$ for 50 seconds and investigated under SEM at 30,000X magnification.

2.2.3. Encapsulation Efficacy. Encapsulation efficiency was determined as the percentage of rhodomyrtone encapsulated in liposome to the original amount of rhodomyrtone added. To determine drug release efficiency of liposome, lipid vesicles were lysed using 100\% Triton X-100 (Baker analyzed, USA). Concisely, $100 \mu \mathrm{L}$ of liposomal suspension was added to $100 \mu \mathrm{L}$ of $100 \%$ Triton X-100 and vortexed for $5 \mathrm{~min}$ to ease lysis of the liposomal encapsulated rhodomyrtone. Free rhodomyrtone was separated from liposome by centrifugation using ultracentrifuge (optima L-100 xp, USA) at $60,000 \mathrm{rpm}, 4^{\circ} \mathrm{C}$ for $2 \mathrm{~h}$. Concentrations of the drug in the filtrate, total drug, and free drug were quantitatively analyzed using HPLC with UV-VIS detection. The encapsulation efficacy was calculated using the following formula:

$$
\operatorname{EE}(\%)=\left[\left(\frac{T-F}{T}\right)\right] \times 100,
$$

where EE is encapsulation efficacy, $T$ is total rhodomyrtone for encapsulation, and $F$ is free drug in sample.

2.3. Quantitative Determination of Active Substances. Quantitative determination of active substances was performed using HPLC Agilent 1100 liquid chromatographic system which consists of an Agilent Chemstation for GC, LC, LC/MSD, CE, UV-VIS detector (Agilent 1100, USA), and A/D Systems-Rev. 08. Ox. An aliquot of $20 \mu \mathrm{L}$ of each sample solution was directly injected into the HPLC system with a mixture of acetonitrile (LB Science Co., Thailand) and water $(85: 15, \mathrm{v} / \mathrm{v})$ as the mobile phase at flow rate of $1.0 \mathrm{~mL} / \mathrm{min}$. Separation was performed in Symmetry C8 analytical column $(4.6 \times 150 \mathrm{~mm}$, particle size, $3 \mu \mathrm{m})$ at $30^{\circ} \mathrm{C}$ and the peak was detected at $254 \mathrm{~nm}$. The column was equilibrated for 6 min before every subsequent run and was saturated with the mobile phase for at least $3 \mathrm{~h}$ before each assay. Rhodomyrtone was used as the internal standard for the assay.

2.4. Method Validation. Analytical validation for rhodomyrtone derived from liposomal preparation was assessed for specificity, linearity, accuracy, precision, limit of detection (LOD), and limit of quantification (LOQ) [24].

2.4.1. Specificity. From HPLC chromatograms, specificity of liposomal encapsulated rhodomyrtone was compared with standard rhodomyrtone. The resolution of the neighbouring peaks, tailing factor, and number of theoretical plates was determined.

2.4.2. Linearity and Range. Linearity of the method was evaluated by processing six calibration curves of rhodomyrtone. Standard solutions containing $1,5,10,20,40$, and $60 \mu \mathrm{g} / \mathrm{mL}$ of rhodomyrtone were prepared and analyzed in triplicate using 


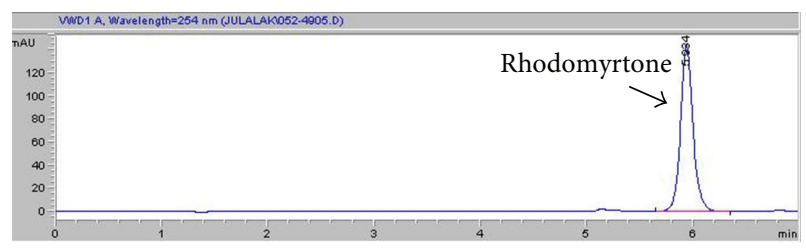

(a)

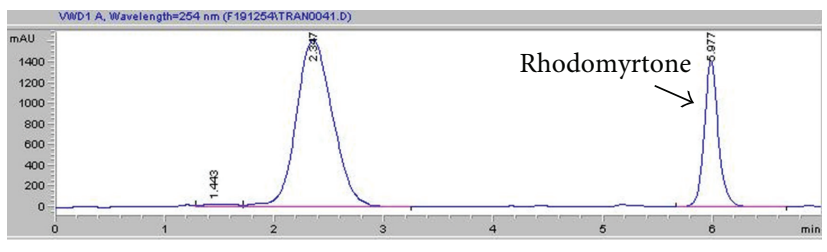

(b)

FIGURE 1: HPLC chromatogram of specificity validation for HPLC analysis of rhodomyrtone after derivatization: (a) pure compound rhodomyrtone $(60 \mu \mathrm{g} / \mathrm{mL})$ and (b) liposomal encapsulated rhodomyrtone $(1,000 \mu \mathrm{g} / \mathrm{mL})$.

HPLC. Peak area ratios between rhodomyrtone and internal standard were plotted against different concentrations of rhodomyrtone. A linear least squares regression analysis was conducted to determine slope, intercept, and coefficient of determination $\left(r^{2}\right)$.

2.4.3. Precision. Both intraday and interday precision experiments were conducted. Standard solution of rhodomyrtone was used to achieve repeatability testing. Data of repeatability was from three separate injections within the same day. Data used to calculate percent recovery of standard (\%RSD) of interday precision was the content of three samples analyzed from three different days (three injections daily).

2.4.4. Accuracy. Accuracy of the method was measured through recovery test of the drug spiked at different concentration levels (low, medium, and high) in the samples. Standard rhodomyrtone stock solution containing $100 \mathrm{mg} / \mathrm{mL}$ was added in increments at five different concentrations (5, $30,200,500$, and $1,000 \mu \mathrm{g} / \mathrm{mL}$ ) to spike the sample solutions. The solutions were filtered through $0.45 \mu \mathrm{m}$ nylon membrane filter and analyzed by HPLC in triplicate.

2.4.5. Limit of Detection (LOD) and Limit of Quantification (LOQ). LOD and LOQ were calculated based on the standard deviation of the regression line or the standard deviation of $y$-intercepts of regression lines and slope. LOD and LOQ were calculated using the following formula:

$$
\mathrm{LOD}=\frac{(3.3 \times \mathrm{SD})}{S}, \quad \mathrm{LOQ}=\frac{(10 \times \mathrm{SD})}{S},
$$

where SD is standard deviation of $y$-intercepts of regression lines and $S$ is slope of standard curve.

2.5. Bacterial Strains and Media. Clinical isolates of multidrug resistant Staphylococcus aureus NPRC 302, 308, 317, and 322; Staphylococcus epidermidis NPRC 529, 537, 573, and 577; and Propionibacterium acnes NPRC 021, 036, and 039 were obtained from the culture collection at Natural Products Research Center, Prince of Songkla University. Reference strains S. aureus ATCC 25923, S. epidermidis ATCC 35984, and P. acne DMST 14916 were included as controls. $S$. aureus and $S$. epidermidis were cultured on MuellerHinton agar (MHA) (Difco, France) at $35^{\circ} \mathrm{C}$ for $24 \mathrm{~h}$. MuellerHinton broth (MHB) (Difco, France) was used for testing antibacterial activity. $P$. acne was cultured in brain heart infusion (BHI) broth (Difco, France) supplemented with 1\% glucose and $0.5 \%$ yeast extract. The bacteria were cultured in an anaerobic atmosphere using BBL GasPak systems (LB Science, Thailand).

2.5.1. Determination of Minimal Inhibitory Concentrations (MICs) and Minimal Bactericidal Concentrations (MBCs). A modified microdilution method [25] was used to determine the MIC of liposomal encapsulated rhodomyrtone. Aliquots $(50 \mu \mathrm{L})$ of liposomal encapsulated rhodomyrtone and rhodomyrtone were diluted in a 96-well microtitre plate to yield final concentrations of $0.25-128 \mu \mathrm{g} / \mathrm{mL}$, and $50 \mu \mathrm{L}$ of MHB was added. One hundred microliter of each bacterial isolate containing approximately $10^{6} \mathrm{CFU} / \mathrm{mL}$ was incubated at $35^{\circ} \mathrm{C}$ for $15 \mathrm{~h}$. After incubation, resazurin (Sigma, Germany), a redox indicator, was added to each well, incubated at $35^{\circ} \mathrm{C}$ for $3 \mathrm{~h}$ (S. aureus and S. epidermidis), and incubated anaerobically at $35^{\circ} \mathrm{C}$ for 3 days (P. acne). MICs were recorded at the lowest concentration of the agent that completely inhibited the bacterial growth from at least 2 out of 3 well. $\mathrm{MBC}$, the lowest concentration of liposomal encapsulated rhodomyrtone completely preventing bacterial growth, was determined with liposomal encapsulated rhodomyrtone that gave MICs by subculturing on fresh MHA ( $S$. aureus and $S$. epidermidis) and BHI agar supplemented with $1 \%$ glucose and $0.5 \%$ yeast extract (P. acne).

\section{Results}

\subsection{Method Development}

3.1.1. Specificity. HPLC chromatograms obtained are shown in Figure 1. From the chromatograms, it was observed that the peak of standard rhodomyrtone and liposomal encapsulated rhodomyrtone sample appeared at the same retention time, about $6 \mathrm{~min}$. No interference of unwanted peaks was observed at the retention time of rhodomyrtone indicating the method is specific.

3.1.2. Linearity and Range. Peak of rhodomyrtone appeared after $6 \mathrm{~min}$ from the start of HPLC. The calibration curve of rhodomyrtone quantitation was linear at the concentrations that ranged from 1 to $60 \mu \mathrm{g} / \mathrm{mL}$. Linear regression equation for rhodomyrtone was $y=23.3804 x-7.6887$. The coefficient of determination $\left(r^{2}\right)$ was greater than 0.999 representing high degree of linearity. 
TABLE 1: Intra- and interday precision study.

\begin{tabular}{lccccc}
\hline Rhodomyrtone $(\mu \mathrm{g} / \mathrm{mL})$ & \multicolumn{3}{c}{$\begin{array}{c}\text { Intraday } \\
\text { Content }(\mu \mathrm{g} / \mathrm{mL})\end{array}$} & Interday \\
& Day 1 & Day 2 & Day 3 & RSD $(\%)$ & Content $(\mu \mathrm{g} / \mathrm{mL})$ \\
\hline 5 & $4.97 \pm 0.61$ & $4.97 \pm 0.61$ & $4.96 \pm 0.28$ & 0.96 & $4.90 \pm 0.45$ \\
30 & $27.71 \pm 2.47$ & $28.20 \pm 2.47$ & $28.89 \pm 1.67$ & 0.90 & $29.94 \pm 2.28$ \\
60 & $57.87 \pm 3.70$ & $58.15 \pm 3.70$ & $59.05 \pm 2.34$ & 0.68 & $58.36 \pm 3.04$ \\
\hline
\end{tabular}

The results are the mean of three independent experiments \pm S.E.

TABLE 2: Results of accuracy determination by recovery study.

\begin{tabular}{lcc}
\hline \multirow{2}{*}{ Spiked concentration $(\mu \mathrm{g} / \mathrm{mL})$} & \multicolumn{2}{c}{ Rhodomyrtone } \\
& Recovery $(\%)$ & RSD $(\%)$ \\
\hline 5 & $98.05 \pm 0.45$ & 1.28 \\
30 & $100.72 \pm 1.02$ & 0.44 \\
200 & $108.91 \pm 3.42$ & 0.28 \\
500 & $102.23 \pm 3.33$ & 0.13 \\
1,000 & $95.78 \pm 4.92$ & 0.09 \\
\hline
\end{tabular}

The results are the mean of three independent experiments \pm S.E.

3.1.3. Precision and Accuracy. Intra- and interday variability was utilized to determine the precision of this newly developed method. It was found that \%RSD ranged from 0.68 to $0.96 \%$ during intraday and 0.67 to $1.28 \%$ during interday precision suggesting that the method is precise (Table 1). Accuracy of the method was measured through recovery test of the drug spiked at high, medium, and low concentrations of the calibration curve. The average percent recovery of rhodomyrtone ranged from 95 to 109\%, proving that the method is highly accurate (Table 2).

3.1.4. Limit of Detection (LOD) and Limit of Quantification (LOQ). LODs and LOQs of the current method were 0.004 and $0.013 \mu \mathrm{g} / \mathrm{mL}$, respectively, indicating that the method was sufficiently sensitive to be used for the drug entrapment study.

\subsection{Formulation and Characterization of Liposomal Encap-} sulated Rhodomyrtone. Characterization of three liposomal formulations with different concentration of lipid prepared by modified ethanol injection method is presented in Table 3.

3.2.1. Size Measurement and $\zeta$-Potential. Range of particle sizes was between 200 and $460 \mathrm{~nm}$. The formulation with lipid $60 \mu \mathrm{mol} / \mathrm{mL}$ exhibited the smallest particle size of $209.56 \pm 4.8 \mathrm{~nm}$, demonstrating electrical polarity and particle distribution. Surface charge of 60,80 , and $100 \mu \mathrm{mol} / \mathrm{mL}$ liposome formulations was $-41.19,-46.29$, and $-50.34 \mathrm{mV}$, respectively.

3.2.2. SEM. All liposomal formulations possess fine sphere shape with relatively monodispersed distributed size (Figure 2).

3.2.3. Entrapment Efficacy. Entrapment efficacy (EE) was calculated as the percentage of liposomal encapsulated

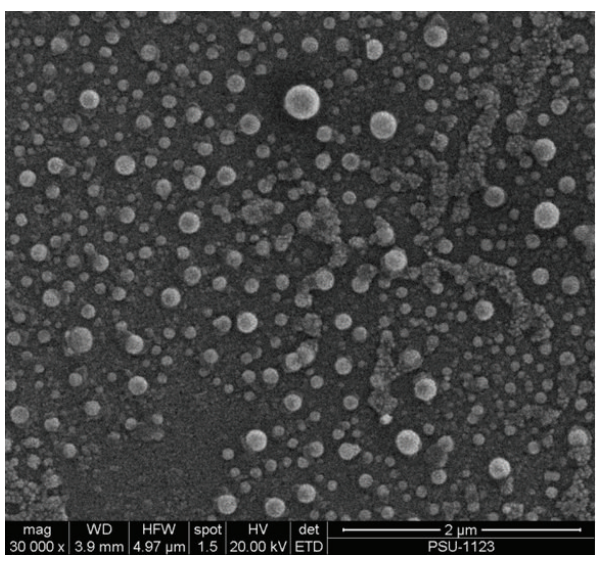

FIGURE 2: Scanning electron micrograph of liposome encapsulated rhodomyrtone formulation. The magnification is $30,000 \mathrm{X}$.

rhodomyrtone. Encapsulation rate of rhodomyrtone content was between $51 \%$ and $65 \%$ of the targeted concentration $(1 \mathrm{mg} / \mathrm{mL})$ in the prototype formulation due to loss of compound during the formulation process. Liposome with total lipid at $60 \mu \mathrm{mol} / \mathrm{mL}$ exhibited greater $\% \mathrm{EE}(65.47 \pm$ $1.7)$ followed by $100 \mu \mathrm{mol} / \mathrm{mL}(63.05 \pm 0.8)$ and $80 \mu \mathrm{mol} / \mathrm{mL}$ $(53.60 \pm 1.2)$ of total lipids containing liposomes.

3.2.4. Physical Appearance. Physical appearance of all liposome formulations (total amount of lipid 60, 80, and $100 \mu \mathrm{mol} / \mathrm{mL}$ ) stored at $4^{\circ} \mathrm{C}$ and $25^{\circ} \mathrm{C}$ for 2 months was evaluated. At the end of the 2 nd month, all the liposomal formulations stored at $4^{\circ} \mathrm{C}$ were stable but slight changes in the colour and viscosity of the liposomal suspension were observed stored at $25^{\circ} \mathrm{C}$. No significant changes in $\% \mathrm{EE}$ were observed in all liposomal formulations. In contrast, significant changes in particle size and $\zeta$-potential were noticed in all liposome formulations stored at $4^{\circ} \mathrm{C}$ and $25^{\circ} \mathrm{C}$.

3.3. MICs and MBCs. MIC and MBC values of liposomal encapsulated rhodomyrtone against 11 clinical isolates and reference strains ranged from 1 to 4 and from 4 to $64 \mu \mathrm{g} / \mathrm{mL}$, respectively, while those of rhodomyrtone were $0.25-1$ and $0.5-2 \mu \mathrm{g} / \mathrm{mL}$, respectively (Table 4 ). Interestingly, liposome formulation was more effective than azelaic acid, benzoyl peroxide, and clindamycin against Staphylococcus aureus ATCC 25923 and Staphylococcus epidermidis ATCC 35984 (Table 5). 
TABLE 3: Stability of different liposomal encapsulated rhodomyrtone formulations.

\begin{tabular}{|c|c|c|c|c|c|c|}
\hline $\begin{array}{l}\text { Total lipid } \\
(\mu \mathrm{mol} / \mathrm{mL})\end{array}$ & $\begin{array}{c}\text { Test } \\
\text { (month) }\end{array}$ & Temp. $\left({ }^{\circ} \mathrm{C}\right)$ & $\begin{array}{c}\text { Particle size } \\
(\mathrm{nm})\end{array}$ & $\begin{array}{c}\zeta \text {-potential } \\
(\mathrm{mV})\end{array}$ & $\begin{array}{l}\text { Entrapment } \\
\text { efficacy (\%) }\end{array}$ & Physical appearance \\
\hline \multirow{7}{*}{60} & 0 & 25 & $209.56 \pm 4.8$ & $-41.19 \pm 1.3$ & $65.47 \pm 1.7$ & Milky suspension \\
\hline & \multirow{2}{*}{2} & 4 & $217.72 \pm 4.1$ & $-34.62 \pm 1.3$ & $64.57 \pm 1.9$ & Milky suspension \\
\hline & & 25 & $220.76 \pm 4.9$ & $-35.98 \pm 2.4$ & $61.88 \pm 1.1$ & Yellow color of milky suspension \\
\hline & \multirow{2}{*}{4} & 4 & $261.24 \pm 7.7$ & $-34.78 \pm 1.5$ & $64.94 \pm 3.2$ & Milky suspension \\
\hline & & 25 & $264.10 \pm 6.7$ & $-34.36 \pm 1.2$ & $61.73 \pm 2.8$ & Yellow color of milky suspension \\
\hline & \multirow{2}{*}{6} & 4 & $262.60 \pm 9.3$ & $-34.91 \pm 2.2$ & $65.49 \pm 2.4$ & Milky suspension \\
\hline & & 25 & $283.26 \pm 8.3$ & $-35.96 \pm 1.6$ & $57.06 \pm 3.1$ & Slightly viscous of yellow milky suspension \\
\hline \multirow{3}{*}{80} & 0 & 25 & $262.24 \pm 5.6$ & $-46.29 \pm 1.2$ & $53.60 \pm 1.2$ & Milky suspension \\
\hline & \multirow{2}{*}{2} & 4 & $419.21 \pm 1.7$ & $-32.36 \pm 1.1$ & $51.87 \pm 1.4$ & Milky suspension \\
\hline & & 25 & $421.63 \pm 0.9$ & $-38.10 \pm 1.6$ & $46.66 \pm 1.2$ & Slightly viscous of yellow milky suspension \\
\hline \multirow{3}{*}{100} & 0 & 25 & $274.64 \pm 0.7$ & $-50.34 \pm 1.3$ & $63.05 \pm 0.8$ & Milky suspension \\
\hline & \multirow{2}{*}{2} & 4 & $438.71 \pm 1.3$ & $-45.54 \pm 1.5$ & $60.91 \pm 1.5$ & Slightly viscous of yellow milky suspension \\
\hline & & 25 & $459.43 \pm 1.4$ & $-41.96 \pm 1.8$ & $60.57 \pm 0.9$ & Slightly viscous of yellow milky suspension \\
\hline
\end{tabular}

The results are the mean of three independent experiments \pm S.E.

TABLE 4: Comparison of minimum inhibitory concentrations (MICs) and minimum bactericidal concentrations (MBCs) of liposomal encapsulated rhodomyrtone formulation at different time against Propionibacterium acnes, Staphylococcus aureus, and Staphylococcus epidermidis.

\begin{tabular}{lcccc}
\hline & \multicolumn{4}{c}{ MICs/MBCs $(\mu \mathrm{g} / \mathrm{mL})$} \\
Isolates & Rhodomyrtone & \multicolumn{3}{c}{ Liposomal formulation } \\
& & Before & After 6 months \\
& & & $4^{\circ} \mathrm{C}$ & $25^{\circ} \mathrm{C}$ \\
\hline Propionibacterium & & & & \\
acnes & & & & \\
NPRC 021 & $0.25 / 0.5$ & $1 / 32$ & $\mathrm{ND}$ & $\mathrm{ND}$ \\
NPRC 036 & $0.25 / 1$ & $2 / 32$ & $\mathrm{ND}$ & $\mathrm{ND}$ \\
NPRC 039 & $0.25 / 1$ & $1 / 8$ & $\mathrm{ND}$ & $\mathrm{ND}$ \\
DMST 14916 & $0.25 / 1$ & $1 / 16$ & $\mathrm{ND}$ & $\mathrm{ND}$ \\
Staphylococcus & & & & \\
aureus & & & & \\
NPRC 302 & $1 / 2$ & $1 / 32$ & $1 / 32$ & $1 / 64$ \\
NPRC 308 & $0.5 / 1$ & $1 / 8$ & $1 / 8$ & $1 / 32$ \\
NPRC 317 & $0.25 / 1$ & $2 / 32$ & $2 / 64$ & $32 / 128$ \\
NPRC 322 & $1 / 2$ & $1 / 16$ & $1 / 32$ & $1 / 64$ \\
ATCC 25923 & $0.25 / 1$ & $1 / 4$ & $1 / 4$ & $1 / 8$ \\
Staphylococcus & & & & \\
epidermidis & & & & \\
NPRC 529 & $0.5 / 1$ & $2 / 64$ & $4 / 64$ & $128 / 128$ \\
NPRC 537 & $0.5 / 2$ & $2 / 32$ & $2 / 32$ & $64 / 64$ \\
NPRC 573 & $0.25 / 2$ & $4 / 32$ & $4 / 32$ & $32 / 64$ \\
NPRC 577 & $0.25 / 1$ & $2 / 32$ & $2 / 32$ & $4 / 64$ \\
ATCC 35984 & $0.25 / 2$ & $2 / 8$ & $2 / 8$ & $4 / 32$ \\
\hline & & & &
\end{tabular}

ND: not done.

\section{Discussion}

Incorporation of compounds in liposome is known to enhance the therapeutic index of antimicrobial drugs, either
TABLE 5: Comparison of minimum inhibitory concentrations (MICs) and minimum bactericidal concentrations (MBCs) of topical drugs and liposomal encapsulated rhodomyrtone against Staphylococcus aureus ATCC 25923 and Staphylococcus epidermidis ATCC 35984 .

\begin{tabular}{|c|c|c|}
\hline \multirow{3}{*}{ Topical drugs } & \multicolumn{2}{|c|}{ MICs/MBCs $(\mu \mathrm{g} / \mathrm{mL})$} \\
\hline & $\begin{array}{c}\text { Staphylococcus } \\
\text { aureus }\end{array}$ & $\begin{array}{c}\text { Staphylococcus } \\
\text { epidermidis }\end{array}$ \\
\hline & ATCC 25923 & ATCC 35984 \\
\hline Azelaic acid $(20 \% \mathrm{w} / \mathrm{w})$ & $256 / 512$ & $64 / 128$ \\
\hline $\begin{array}{l}\text { Benzoyl peroxide }(2.5 \% \\
\mathrm{w} / \mathrm{w})\end{array}$ & $>1024$ & $>1024$ \\
\hline Clindamycin $(1 \% \mathrm{w} / \mathrm{v})$ & $1 / 64$ & $>1024$ \\
\hline $\begin{array}{l}\text { Liposomal encapsulated } \\
\text { rhodomyrtone }\end{array}$ & $1 / 4$ & $2 / 8$ \\
\hline
\end{tabular}

by increasing the drug concentration in bacterial cells or by decreasing the exposure in normal host tissues. Phosphatidylcholine is a main lipid constituent of several commercially available liposome products due to neutral charge and its nontoxic biodegradable profile. Liposomes dispersed in aqueous solution generally face physical and chemical instabilities after long-term storage. Hydrolysis and oxidation of phospholipids and liposome aggregation are the common cause of liposome instabilities [26]. The incorporation of cholesterol within phosphatidylcholine liposomes enhances liposome stability, modulates rigidity, and reduces serum induced stability [27]. However, a balanced concentration of cholesterol is essential to form stable liposomes to prevent leakage, while excess or deficit of cholesterol could result in destabilization of lipid bilayer membrane leading to decreased drug entrapment and increased leakage [28].

In view of the above advantage of liposome mediated delivery systems, we have encapsulated rhodomyrtone in liposome formulations with total lipids content of 60,80 , and $100 \mu \mathrm{mol} / \mathrm{mL}$ by modified ethanol injection methods. 
Rhodomyrtone was encapsulated in liposome by physical entrapment in lipid phase of liposome. There were no chemical reactions between liposome constituents and drug as revealed by appearance of the peak in HPLC at the same retention time for liposome encapsulated rhodomyrtone and free rhodomyrtone. The method was specific since the recovery of the drug was almost $100 \%$. The particle size of higher lipid content liposome was slightly higher than the liposome with lower lipid content. The size of particles increased during storage which may be due to aggregation or fusion of liposomes. The negative charge of liposome formulation was due to the presence of cholesterol on the surface of liposome. The charge on the liposome depends on the head group composition of lipid and $\mathrm{pH}$ of the solution. The bigger sized liposome was found more negatively charged, compared with smaller liposome, because the tendency of zeta potential increased when total lipid content increased [28]. The amount of charge on the surface of liposome influences stability, kinetics, biodistribution, and interactions with the targeted cells. Higher charges on particles produce strong repulsive force between same charge particles that keep the particles away from each other and make the particles more stable. Negatively charged liposomes are less prone to aggregation and comparatively more stable in suspension [29]. During storage the charge on liposome decreased due to aggregation of liposomal particles and decrease in total surface area.

In general, the $\mathrm{EE}$ of lipid soluble drugs is higher at higher lipid concentration. However, in the present study, we did not observe any significant difference in EE between 60, 80 , and $100 \mu \mathrm{mol} / \mathrm{mL}$ total lipid content liposome. During storage at different temperatures also the $\mathrm{EE}$ was stable even after 2 months which may be because of the ratio of phosphatidylcholine and cholesterol that made the liposome stable and prevented leakage during storage. There was no visible aggregation of particles observed with storage as precipitate was not found in the liposomal suspension. There were no effects of storage temperature on particle size, zeta potential, and $\mathrm{EE}$ when liposomes were stored at 4 and $25^{\circ} \mathrm{C}$. Similar trends of change in size, zeta potential, and EE were observed when liposome was stored at both temperatures. However, slight change in colour and viscosity was observed in the liposomes stored at $25^{\circ} \mathrm{C}$.

Although the MIC and MBC values of liposomal encapsulated rhodomyrtone were acceptable, they were comparatively higher than the free rhodomyrtone. This could be due to slow release of rhodomyrtone from liposome into the bacterial cells. Free rhodomyrtone can interact with bacterial cells directly and act faster compared with liposomal encapsulated rhodomyrtone. In contrast, higher efficacy of liposomal encapsulated drugs was reported, compared with free drugs [30, 31]. Moreover, enhanced antibacterial activity of liposomal encapsulated amikacin against E. coli, S. faecalis, and $S$. aureus was observed whereas reduced activity against $P$. aeruginosa was observed [32]. In general, liposomes fuse with bacterial outer membrane and release their contents into the cells [30]. Drugs which face physical barrier in penetration to bacterial cells could be improved by forming liposomal formulations that increase the concentration of drug inside bacterial cells for the drugs. Since the present liposomal formulation releases drugs slowly, higher drug dose can be applied for slow and controlled releases of drug at the target site and make the host cells less prone to side effects of drug.

\section{Conclusion}

A simple and inexpensive simultaneous HPLC method for the measurement of rhodomyrtone employing UVVIS detection was developed and successful in analysis of liposomal encapsulated rhodomyrtone samples. The present study demonstrated potent antimicrobial activity of liposomal encapsulated rhodomyrtone which may be useful in the treatment of acne vulgaris. Although the antibacterial effects of liposomal encapsulated rhodomyrtone against $P$. acnes, S. aureus, and S. epidermidis were demonstrated, their mechanism remains unknown. Further research is needed to evaluate skin permeability and clinical trials of liposomal encapsulated rhodomyrtone.

\section{Conflict of Interests}

The authors declare that they have no conflict of interests.

\section{Acknowledgments}

This work was supported by the Higher Education Research Promotion and National Research University Project of Thailand, Office of the Higher Education Commission.

\section{References}

[1] A. T. Shamban and V. A. Narurkar, "Multimodal treatment of acne, acne scars and pigmentation," Dermatologic Clinics, vol. 27, no. 4, pp. 459-471, 2009.

[2] N. Janiczek-Dolphin, J. Cook, D. Thiboutot, J. Harness, and A. Clucas, "Can sebum reduction predict acne outcome?" British Journal of Dermatology, vol. 163, no. 4, pp. 683-688, 2010.

[3] T. H. Tsai, T. H. Tsai, W. H. Wu, J. T. P. Tseng, and P. J. Tsai, "In vitro antimicrobial and anti-inflammatory effects of herbs against Propionibacterium acnes," Food Chemistry, vol. 119, no. 3, pp. 964-968, 2010.

[4] B. Wei, Y. Pang, H. Zhu et al., "The epidemiology of adolescent acne in North East China," Journal of the European Academy of Dermatology and Venereology, vol. 24, no. 8, pp. 953-957, 2010.

[5] J. J. Leyden, N. Preston, C. Osborn, and R. W. Gottschalk, "Invivo effectiveness of adapalene $0.1 \%$ / benzoyl peroxide $2.5 \%$ gel on antibiotic-sensitive and resistant Propionibacterium acnes," Journal of Clinical and Aesthetic Dermatology, vol. 4, no. 5, pp. 22-26, 2011.

[6] H. C. Williams, R. P. Dellavalle, and S. Garner, "Acne vulgaris," The Lancet, vol. 379, pp. 361-372, 2012.

[7] W. P. Bowe, J. B. Glick, and A. R. Shalita, "Solodyn and updates on topical and oral therapies for acne," Current Dermatology Reports, vol. 1, no. 3, pp. 97-107, 2012.

[8] W. Koltun, J. M. Maloney, J. Marr, and M. Kunz, “Treatment of moderate acne vulgaris using a combined oral contraceptive containing ethinylestradiol $20 \mu \mathrm{g}$ plus drospirenone $3 \mathrm{mg}$ administered in a 24/4 regimen: a pooled analysis," European 
Journal of Obstetrics Gynecology and Reproductive Biology, vol. 155, no. 2, pp. 171-175, 2011.

[9] J. K. L. Tan and C. Ediriweera, "Efficacy and safety of combined ethinyl estradiol/drospirenone oral contraceptives in the treatment of acne," International Journal of Women's Health, vol. 1, no. 1, pp. 213-221, 2009.

[10] A. Kadri, Z. Zarai, I. B. Chobba et al., "Chemical composition and antioxidant activity of Marrubium vulgare L. essential oil from tunisia," African Journal of Biotechnology, vol. 10, no. 19, pp. 3908-3914, 2011.

[11] M. T. Chomnawang, S. Surassmo, K. Wongsariya, and N. Bunyapraphatsara, "Antibacterial activity of thai medicinal plants against methicillin-resistant Staphylococcus aureus," Fitoterapia, vol. 80, no. 2, pp. 102-104, 2009.

[12] J. Kubola and S. Siriamornpun, "Phytochemicals and antioxidant activity of different fruit fractions (peel, pulp, aril and seed) of Thai gac (Momordica cochinchinensis Spreng)," Food Chemistry, vol. 127, no. 3, pp. 1138-1145, 2011.

[13] S. Limsuwan, A. Hesseling-Meinders, S. P. Voravuthikunchai, J. M. Van Dijl, and O. Kayser, "Potential antibiotic and antiinfective effects of rhodomyrtone from Rhodomyrtus tomentosa (Aiton) Hassk. on Streptococcus pyogenes as revealed by proteomics," Phytomedicine, vol. 18, no. 11, pp. 934-940, 2011.

[14] J. Saising, M. Ongsakul, and S. P. Voravuthikunchai, "Rhodomyrtus tomentosa (Aiton) Hassk. ethanol extract and rhodomyrtone: a potential strategy for the treatment of biofilm-forming staphylococci," Journal of Medical Microbiology, vol. 60, no. 12, pp. 1793-1800, 2011.

[15] W. Sianglum, P. Srimanote, W. Wonglumsom, K. Kittiniyom, and S. P. Voravuthikunchai, "Proteome analyses of cellular proteins in methicillin-resistant Staphylococcus aureus treated with rhodomyrtone, a novel antibiotic candidate," PLoS ONE, vol. 6, no. 2, Article ID e16628, 2011.

[16] K. M. Geetha, C. Sridhar, and V. Murugan, "Antioxidant and gastroprotective activities of Rhodomyrtus tomentosa (Ait.) Hassk," International Journal of PharmTech Research, vol. 2, no. 1, pp. 283-291, 2010.

[17] K. K. Upadhyay, A. N. Bhatt, A. K. Mishra et al., "The intracellular drug delivery and anti tumor activity of doxorubicin loaded

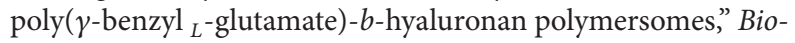
materials, vol. 31, no. 10, pp. 2882-2892, 2010.

[18] Y. Fan, D. Wang, Y. Hu et al., "Liposome and epimedium polysaccharide-propolis flavone can synergistically enhance immune effect of vaccine," International Journal of Biological Macromolecules, vol. 50, no. 1, pp. 125-130, 2012.

[19] H. S. Chiong, M. N. Hakim, M. R. Sulaiman et al., "Development and characterisation study of liposomes-encapsulated piroxicam," International Journal of Drug Delivery, vol. 3, no. 1, 2011.

[20] C. Kelly, C. Jefferies, and S. A. Cryan, "Targeted liposomal drug delivery to monocytes and macrophages," Journal of Drug Delivery, vol. 2011, Article ID 727241, 11 pages, 2011.

[21] D. Dachriyanus, S. Salni, M. V. Sargent et al., "Rhodomyrtone, an antibiotic from Rhodomyrtus tomentosa," Australian Journal of Chemistry, vol. 55, no. 3, pp. 229-232, 2002.

[22] Y. Maitani, S. Igarashi, M. Sato, and Y. Hattori, "Cationic liposome (DC-Chol/DOPE $=1: 2$ ) and a modified ethanol injection method to prepare liposomes, increased gene expression," International Journal of Pharmaceutics, vol. 342, no. 1-2, pp. 3339, 2007.

[23] J. A. Davies, G. K. Anderson, T. J. Beveridge, and H. C. Clark, "Chemical mechanism of the gram stain and synthesis of a new electron-opaque marker for electron microscopy which replaces the iodine mordant of the stain," Journal of Bacteriology, vol. 156, no. 2, pp. 837-845, 1983.

[24] AOAC International, AOAC Guidelines for Single Laboratory Validationof Chemical Methods for Dietary Supplements and Botanicals, AOAC International, Gaithersburg, Md, USA, 2002.

[25] CLSI: Clinical Laboratory Standards Institute, "Methods for dilution antimicrobial susceptibility tests for bacteria that grow aerobically; approved standard," in Clinical and Laboratory Standards Institute Document M07-A8, Clinical and Laboratory Standards Institute, Wayne, Pa, USA, 8th edition, 2009.

[26] C. Chen, D. Han, C. Cai, and X. Tang, "An overview of liposome lyophilization and its future potential," Journal of Controlled Release, vol. 142, no. 3, pp. 299-311, 2010.

[27] A. R. Mohammed, N. Weston, A. G. A. Coombes, M. Fitzgerald, and Y. Perrie, "Liposome formulation of poorly water soluble drugs: optimisation of drug loading and ESEM analysis of stability," International Journal of Pharmaceutics, vol. 285, no. 1-2, pp. 23-34, 2004.

[28] N. Langlah and S. Pinsuwan, "Preparation and physicochemical study of liposomes containing nicotinamide," in Proceedings of the 7th IEEE International Conference on Nano/Micro Engineered and Molecular Systems (NEMS '12), pp. 537-541, 2012.

[29] T. Lian and R. J. Y. Ho, "Trends and developments in liposome drug delivery systems," Journal of Pharmaceutical Sciences, vol. 90, no. 6, pp. 667-680, 2001.

[30] M. Halwani, C. Mugabe, A. O. Azghani, R. M. Lafrenie, A. Kumar, and A. Omri, "Bactericidal efficacy of liposomal aminoglycosides against Burkholderia cenocepacia," Journal of Antimicrobial Chemotherapy, vol. 60, no. 4, pp. 760-769, 2007.

[31] C. Mugabe, M. Halwani, A. O. Azghani, R. M. Lafrenie, and A. Omri, "Mechanism of enhanced activity of liposome-entrapped aminoglycosides against resistant strains of Pseudomonas aeruginosa," Antimicrobial Agents and Chemotherapy, vol. 50, no. 6, pp. 2016-2022, 2006.

[32] M. Mirzaee, P. Owlia, M. Mehrabi, and A. Gharib, "In vitro bactericidal activity of encapsulated amikacin in liposome," Iran Journal of Pathology, vol. 4, no. 4, pp. 151-156, 2009. 


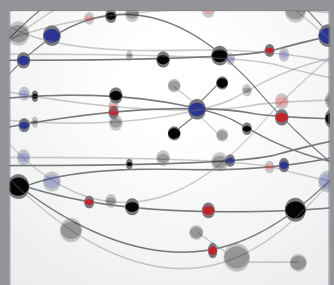

The Scientific World Journal
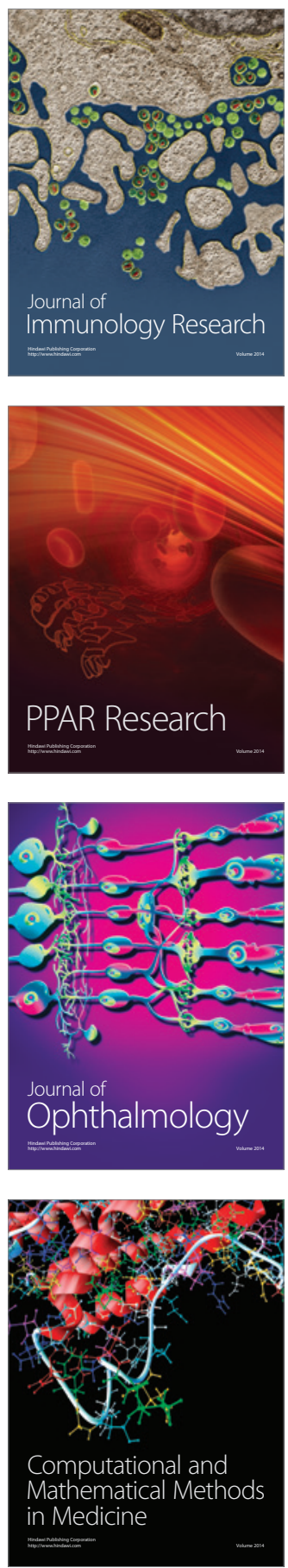

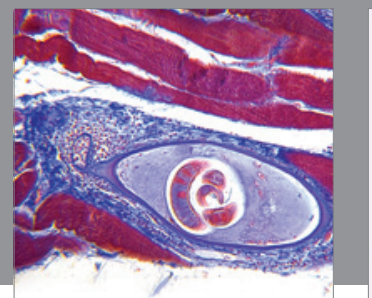

Gastroenterology

Research and Practice
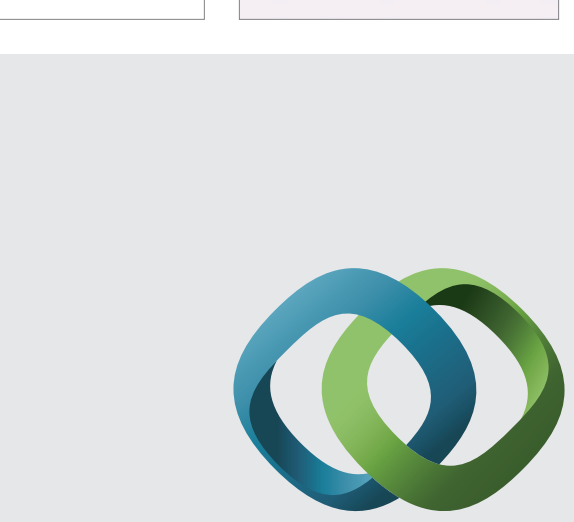

\section{Hindawi}

Submit your manuscripts at

http://www.hindawi.com
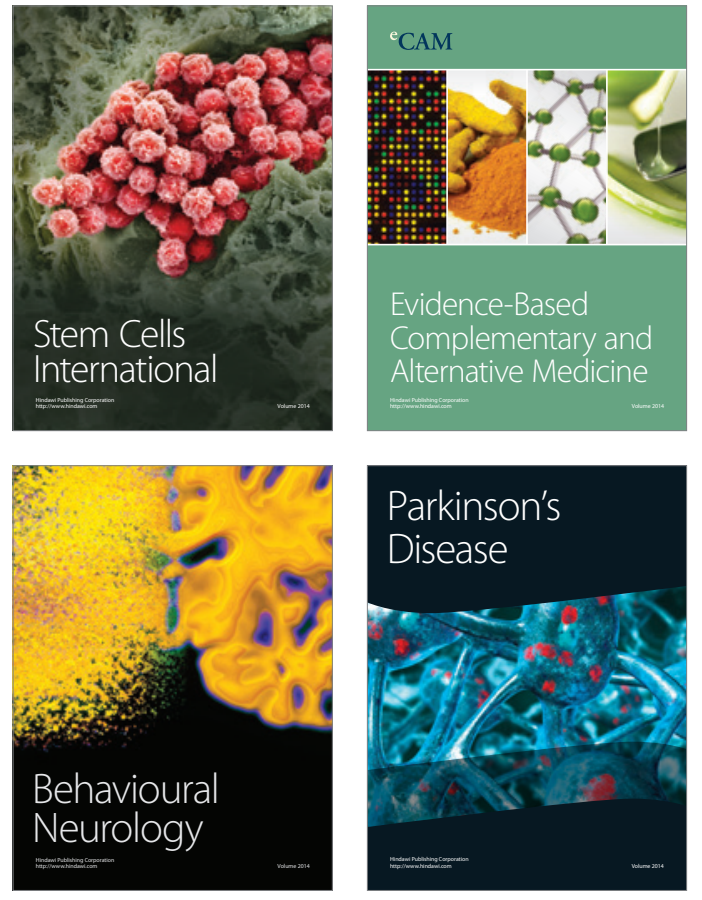
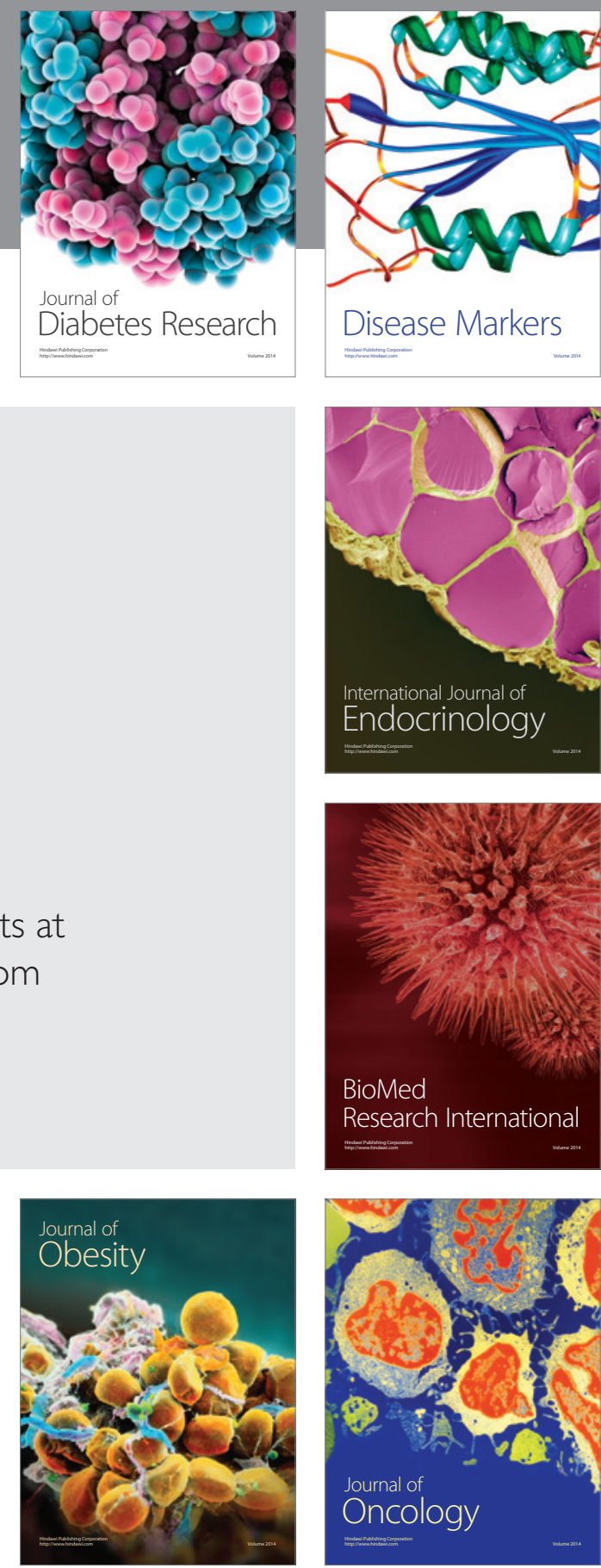

Disease Markers
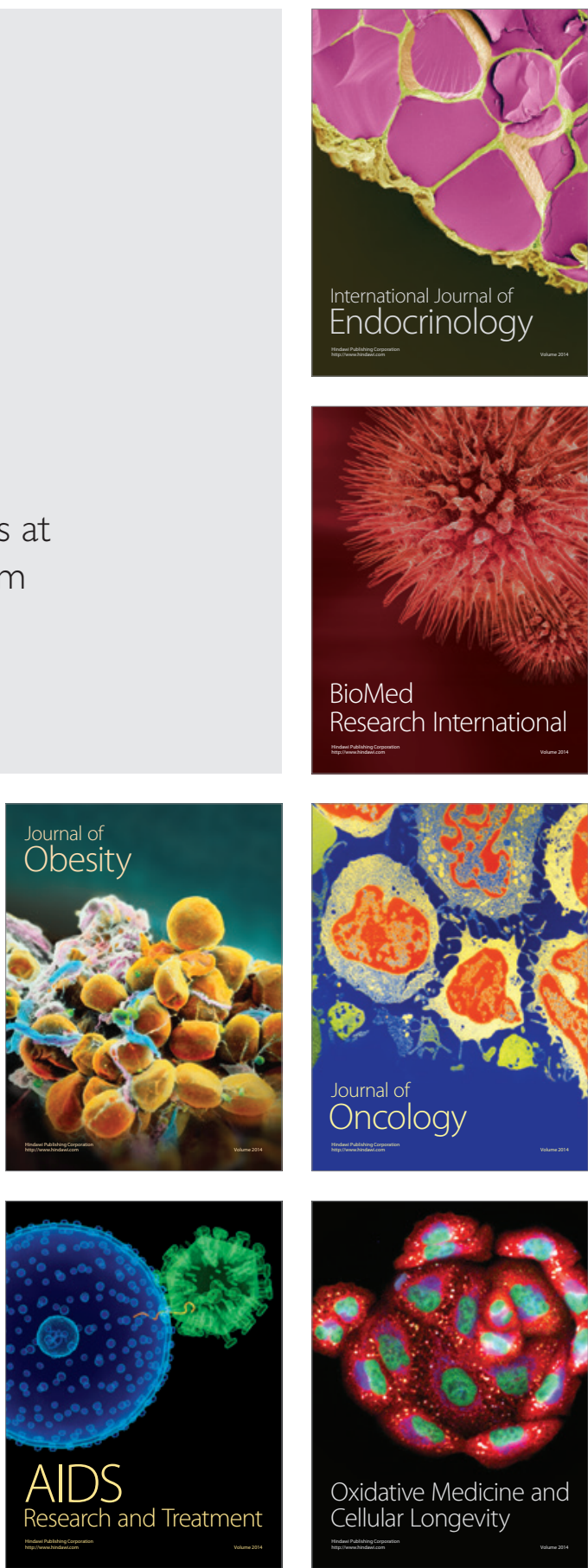